\title{
Argumentation in Science Education as an Evolving Concept: Following the Object of Activity
}

\begin{abstract}
The paper argues that the way we realise or define argumentation in a research project aiming at promoting the practice in primary science education should not be considered as something static and pre-given but may change during the various phases of the project, based on stakeholders' motives and needs. This claim is supported through the findings of a two-year empirical study that took place in Cyprus, which illustrate in detail the transformations that the definition and meaning of argumentation in primary science education went through. Activity theory is used as a theoretical, methodological and analytical framework. Specifically, the paper mainly draws on the notion of the object of the activity, used as a conceptual heuristic, and on the notions of the springboard and the microcosm from expansive learning theory, used as methodological and analytical tools, in order to trace the various definitions and meanings attributed to argumentation by stakeholders. Implications for research and the assessment of teachers are also presented.
\end{abstract}

Keywords: argumentation; science education; activity theory; activity system; object

Acknowledgements. The first author would like to thank Professor [name1], [name2] and people at [name3] for their invaluable feedback on the paper, during the author's visit at the center [details omitted to protect the anonymity of the paper]. Also, the first author would like to thank the teachers who participated in the research, without whom the project would not have come into life.

\section{Introduction and Research Aim}

Argumentation in science education is considered to be a core practice that can empower students develop their reasoning skills, criteria for knowledge evaluation, attain scientific literacy and other subsidiary skills (e.g., Kelly, Druker, \& Chen, 1998; Jiménez-Aleixandre \& Erduran, 2008; Berland \& Reiser, 2009; Erduran, Ozdem, \& Park, 2015). Many researchers suggest that argumentation is a skill that can be developed (e.g., Kuhn, 1991; Mason, 1996), either by explicitly teaching argumentation (e.g., Zohar \& Nemet, 2002; Osborne, Erduran, \& Simon, 2004) or by creating the conditions through which students engage with argumentative discourse through appropriate activities (e.g., Duschl \& Osborne, 2002; Kuhn, Kenyon, \& Reiser, 2006; Martin \& Hand, 2009).

Various definitions of argumentation exist in science education research. van Eemeren and Grootendorst define it as the "verbal, social and rational activity aimed at convincing a reasonable critic of the acceptability of a standpoint by putting forward a constellation of propositions justifying or refuting the proposition expressed in the standpoint" (van Eemeren \& Grootendorst, 2004, p.1), emphasising thus argumentation as a social and rational activity. Kuhn and Udell (2003) suggest a similar definition, proposing that argumentation is "the dialogic process in which two or more people engage in debate of opposite claims" through which an evaluation and justification of claims to scientific knowledge takes place (p.1245). Moreover, according to Naylor, Keogh and Downing (2007), argumentation is regarded as the process of 
evaluating and justifying claims. Author et al. propose that argumentation may be seen [quotation removed to protect anonymity], while Jiménez-Aleixandre, Agraso and Eirexas understand argumentation as "the capacity of relating data and evidence to theoretical claims, the capacity of choosing among several alternatives using reasoned criteria" (2004, p.2). Furthermore, on a more structural account of the argument, used by various researchers in their projects (e.g., Kelly \& Takao, 2002; Erduran, Simon, \& Osborne, 2004; Clark, Sampson, Weinberger, \& Erkens, 2007), Toulmin (2003) suggests that an argument is a pattern of five constituent components; the claim, the data, the warrant, the backing and the rebuttal. A claim is regarded as the initial assertion in which we commit ourselves, data as the facts that seem to support this initial assertion, and the warrant as the supplementary and explanatory statement that may help us validate and authorise the step we take to present certain data as the basis of a certain claim. As the warrant is hypothetical, we may also present a backing which is an assurance to establish the authority of the warrant. Finally, we may also put forward rebuttals to express any conditions of exceptions which reduce the warrant's strength and authority.

The main aim of our paper though, is to illustrate that, regardless of the initial definition or meaning given to argumentation at the beginning of a research project, what argumentation means for stakeholders may change during the various phases of the project, acquiring different identities and definitions. Argumentation's definition and meaning that is, seems as an evolving concept and as a trajectory rather than a static, pre-defined and pre-given entity in science education practice. Put in the form of a research question, our research tries to respond to the following question:

- how is the initial definition of argumentation in primary science education being re-adapted and re-formulated by stakeholders (e.g., teachers, the science inspector) during the various phases of a research project, based on their own needs and motives?

Our research project managed to do this by following "argumentation" as the object of the activity of argumentation instruction in primary science education and by tracing and portraying its evolution and the various transformations that it went through, during a two-year research process. In order to achieve this, activity theory (e.g., Vygotsky, 1978; Leont'ev, 1978; Engeström, 1987) was used as a theoretical, methodological and analytical framework. Specifically, the paper mainly draws on the notion of the object of the activity used as a conceptual and methodological heuristic and on the notions of the springboard and the microcosm from expansive learning theory, used as methodological and analytical tools.

The paper begins with a brief presentation of the concept of the object-driven activity in respect to argumentation and continues with an overview of the concept of the object, introduced through the work of Marx (1973), who laid, amongst others, the philosophical foundation of activity theory, Leont'ev $(1978,1981)$ and Engeström (1987) (section 2). A following section (section 3) presents the methodology of the research, presenting a rationale for following the object of the activity as a methodological and analytical tool and the specific research and analytical processes of the study. The Findings section (section 4) reports on the various transformations that argumentation as the object of activity seemed to go through during the two years the research was running. The importance of the findings and the practical implications deriving from them are being discussed in the Discussion section (section 5).

\section{The Object-Driven Activity}

\subsection{Argumentation as an Object-Driven Systemic Activity}


According to activity theory, human praxis is realised in the form of activities, as individual actions are insufficient to explain human behaviour and may appear meaningless outside the collective activities in which they occur (Leont'ev, 1978, 1981). The important aspect that should be bear in mind though, as Leont'ev (1978) emphasised, is that behind every activity there is a need that the activity aims to satisfy. Activities comprise of actions which are directed towards a specific goal, even though they are still stimulated by the activity's motive (Leont'ev, 1978, 1981). Actions comprise of operations which relate to the conditions that enable their materialisation and may be considered as automatized or routinised actions. Engeström (1987) expanded this initial approach of the concept of the activity by realising activities as historically accumulated, multi-voiced, object-driven systemic wholes that can be portrayed by using the activity system model (Figure 1).

In a paper that was published recently (Authors), we have portrayed that the practice of argumentation instruction may exist not only as an action but also as a discrete systemic activity within the broader activity of science education, following the definition of the activity as it was given by Engeström (1987). "Argumentation", as the main motive of this activity system, was considered as being the object of the activity and was defined by participants as the skill that students should have or attain in order to express the knowledge they obtain to support a claim or for making links between facts they learn or for transferring the attained knowledge into instances of their everyday life. In this paper though, we try to illustrate that, regardless of the initial definition or meaning given to "argumentation" as the object of the activity, what this concept means to stakeholders may change during the various phases of a research project, acquiring different identities and definitions based on stakeholders' needs and motives observed in their real environment; a process through which the concept of argumentation is formed "in the wild", as Engeström and Sannino (2012) note, where "human cognition and action are never predictable and programmable" (p.206).

In order to theoretically and analytically support this claim, we draw from the work of Marx (1973), Leont'ev (1978, 1981) and Engeström (1987), whose work was seminal in introducing and expanding the concept of the object within the doctrine of activity theory (Kaptelinin, 2005). The specific theoretical concepts that were used for the scope of this paper are following presented in separate sub-sections.

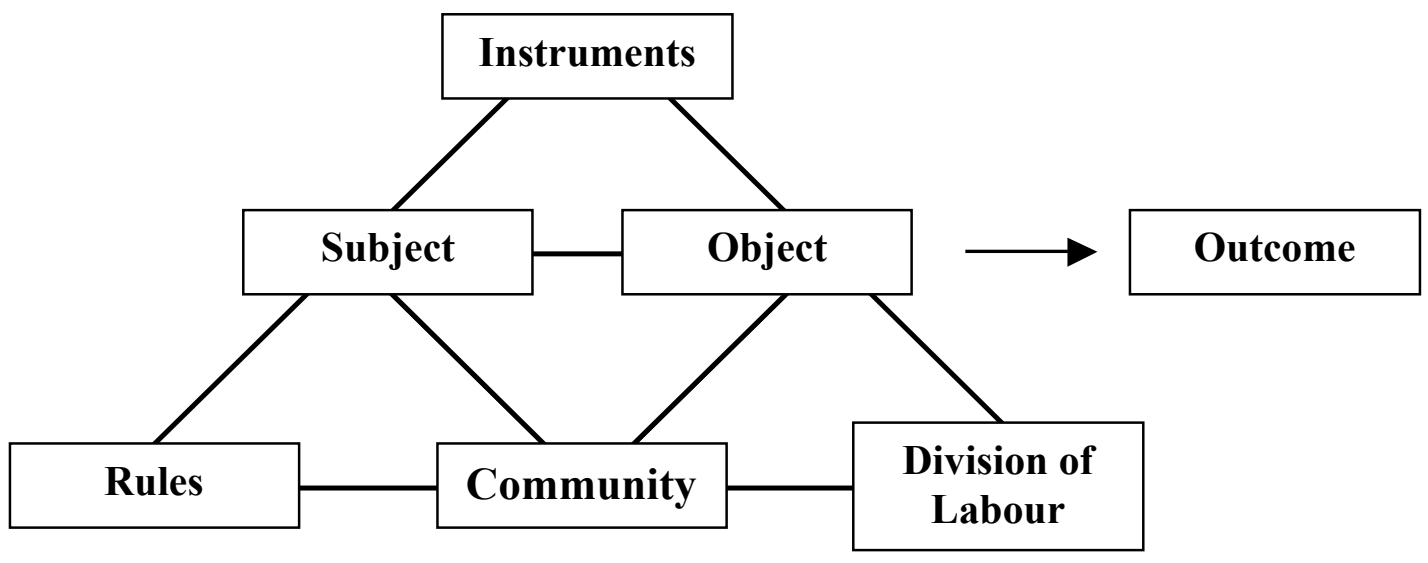

Figure 1. The expanded activity system model (Engeström, 1987). 


\subsubsection{Karl Marx's Contribution}

The way Marx approached the concept of the object is made evident through a discussion he engages with about the processes of production, distribution, exchange and consumption of products, which he regarded as the object of this process (Marx, 1973). Through Marx's description of these four, the process that an object follows, from its production and its introduction in a context to its possible transformation based on the subjects' needs and motives, can be realised. Marx's ideas were important to our work when trying to understand the evolutionary process that argumentation went through during our two-year research project, described in section 4 .

Production is defined as the creation of products by individuals in society according to their needs. Distribution is seen as the determination and division of the 'proportion in which the individual shares in the product' according to social laws (Marx, 1973, p.88-89) while exchange is defined as the actual delivery of these proportionately shared products to individuals, according to individual needs. Finally, consumption is seen as the process through which the objects of this process, the products that is, are being enjoyed and consumed by individuals to satisfy their own individual needs. The life-time of a product thus follows a process through which it is firstly being conceptualised and produced by social individuals based on certain needs, it then steps outside the societal boundary, it is objectified and assumes the role of serving these pending individual needs that exist, according to certain social laws. Even though Marx (1973) expressed the above thoughts concerning the object in relation to sensuous, commodified, material objects, it is evident that in other instances he recognised and highlighted that objects could also be thought objects as well (Marx, 1932). In our study, the concepts of production, distribution, exchange and consumption were used to make sense of the evolutionary process that argumentation followed by being distributed to individual participants as a given object and was then exchanged and consumed by them in order to serve their specific needs and motives, presented in section 4.3.2.

Concerning the interrelation of the four processes that Marx (1973) referred to, the most relevant issue to the scope of our research refers to the process of consumption. Specifically, Marx suggested that production seems to mediate consumption, as its purpose is to create and provide the material, external object for consumption while at the same time consumption mediates production as its role is to create and shape the subject that will consume the product and consequently, create and reproduce the need, the motive and the purpose of production. Consequently, it seems that "the product only obtains its 'last finish' in consumption" and "becomes a real product only by being consumed" (Marx, 1973, p.91). These issues relate to how argumentation as the object of our activity seemed to obtain its "last finish" in our research study, only by being exchanged and consumed by the teachers who implemented it in primary science practice; an issue to be discussed in following sections of the paper (section 4.3), when we examine the various transformations that the concept of argumentation went through.

Additionally, Marx (1973) introduced the concepts of the use value and the exchange value of the objects through which a further understanding of the nature of commodified objects can be grasped. A commodified object refers to any object that has value which is determined by the amount of social labour required to be produced. The use value of a commodified object refers to the value that it initially has as a useful product intended to satisfy a social need, by having the possibility to be exchanged. The exchange value of a commodity refers to the value that it acquires due to its exchangeability between individuals and could be influenced by some explicit or implicit social conditions. The exchange value of the commodity is what attributes to 
it a social character and a uniform social status, not otherwise capable of being revealed. Marx (1973) and Engeström (1987) suggest that activities can be commodified as well, and as such, can also acquire a use and exchange value. Within the scope of our own research study, the concepts of the use value and exchange value contributed in helping us conceptualise certain events as tensions between these two values, which led to one of the transformation of the object of argumentation observed in our research study, presented in section 4.3.2.

\subsubsection{Alexei Leont'ev's Contribution}

Leont'ev $(1978,1981)$ suggested that the object of an activity is its true motive, without which the activity does not exist. It is thus meaningless to refer to 'non-motivated' activity (Leont'ev, 1978, section 3.5). Even though Leont'ev (1978) expressed the opinion that the object or the motive of the activity may be difficult to be realised by the individual, he highlighted (Leont'ev, 1981) that the concept of the object should not be limited to something towards an individual relates itself in a passive way but the element towards which an individual relates itself in an active, striving or impassioned way; emphasising in this way the active role of individuals concerning to which their actual object is (Leont'ev, 1981).

Further, Leont'ev (1978) proposes that the object of the activity is not only related to proper cognitive processes that take place but also to needs and emotions that exist. Initially, a need may appear as a condition in itself with no power to influence, direct or regulate the activity; the need may be realised as existing but still not capable of inducing productive actions within the activity. This becomes possible only when the need meets an object that could answer it; an object thus, is a condition so that a need can direct the activity on the part of the subject. This process is named as the objectification of the need (Leont'ev, 1978).

The way that Leont'ev $(1978,1981)$ approached the concept of the object, emphasising the active role of individuals in relating to the object of the activity through the process of the objectification of the need, contributed in realising the way our participating teachers engaged in a process of actively reshaping argumentation as the object of the activity, based on their pending needs, emotions and past experiences, discussed in section 4.2 and 4.3.

\subsubsection{Yrjö Engeström's Contribution}

The societal character that Engeström $(1987,2005)$ attributed to the notion of the object is probably his most important contribution, compared with the work of Leont'ev $(1978,1981)$ and Marx (1973). As objects are conceptualised and constructed by actors, who are functioning not as isolated units but are interacting in a collective, spatial and temporal way, they seem to be acquiring "historical dynamics and trajectories of their own" (Engeström, 2005a, p.93). Without examining the cultural-historical construction and content of objects, our understanding of activity and cognition remains formal and superficial (Engeström, 1995).

Engeström highlights that the object of an activity should be considered as 'a project under construction' (2005b, p.184) and a constantly changing target that cannot be standardised or reduced to a series of conscious short-term actions (Engeström, 2001, 2005b, 2006); it may both be given to the participants and be anticipated, projected and reconstructed by them (Engeström, 1995, 2001, 2005a). The object may be given as raw material to subjects who may re-interpret it, reconstruct it and reshape it into a meaningful outcome or an entity of dynamic nature that is in a process of a constant movement towards new goals; in this sense, the object could be considered as deeply biased and subjective (Engeström, 2006). Nevertheless, Engeström (e.g., 2004, 2005) emphasises that the object should neither be confused with the raw 
material given nor with the end product achieved but it should be realised as a trajectory which is realised as the complete process that takes place in order to advance from given raw material to an attained, dynamically evolving entity. The effort should focus that is, on locating the various "instantiations of the object" (Engeström, 2005c, p.150) which are said to be the elements and features of the object or the activity system that may be changing and what dynamically evolving consequences these alterations seem to induce.

The reconstruction and reshaping of the object may be achieved through the participants' actions by choosing the appropriate properties that seem fruitful for their activity, as the object's multifaceted nature and inherent subjectivity allows a multiplicity of interpretations (Engeström, 1995). As each individual participant in the activity may perceive and personify the object in his own unique and meaningful way, multiple perspectives of how the object is realised may be noticed within the same activity (Engeström, 1995, 2000). The object thus seems to be following a course from an initial state of an "unreflected, situationally given 'raw material' to a "collectively meaningful object constructed by the activity system” (Engestrom, 2001, p.63).

\section{Methods}

\subsection{Following the Object of Activity}

The paper's aim, as a reminder to the reader, is to illustrate that, regardless of the initial definition or meaning given to "argumentation" as the object of the activity, what this concept means to stakeholders may change during the various phases of the project, acquiring different identities and definitions. This will be achieved by following "argumentation" as the object of the activity of argumentation instruction in science education during a two-year research effort that took place in Cyprus, through a process similar to those suggested or followed in other studies (e.g., Engeström, Puonti, \& Seppänen, 2003; Engeström, Engeström, \& Kerosuo, 2003; Engeström, 2004; Nicolini, 2007).

A choice to follow the object and not the actions of the various actors of the activity system (e.g., teachers, science inspector) was made based on methodological choices that needed to be made, when we realised that the concept of the object was the common idea underlying and linking together the various facets of the findings of our research study, similarly to what Engeström, Engeström and Kerosuo (2003) argue in their own study: "that the necessary glue is focus on the object of professional work and discourse...[as it] can keep radically distributed work and expertise together, coordinated and capable to act in concert when needed' (p.307).

Additionally, we have also come to realise that following the object of the activity rather than the actors, proved to be a more reliable and prudent methodological choice for our research project, since three of the five teachers who participated during the first year of the research project chose not to participate during the second year, making the process of following the actors' actions unreliable as a research strategy. This realisation seems to be in full accord to what Engeström (2004) notes in his own study, that "Actors become dispersed and replacable which renders the focus on actors increasingly vulnerable as a research strategy" (p.17). Actors were not of course ignored in our project, since the object of the activity of argumentation instruction was given a voice and was negotiated through the discussions in which participants were involved in.

Furthermore, the object of the activity is also put forward as a reliable analytical tool, used, as Kaptelinin (2005) argues, as "the sense-maker" (p.5) of what and why people are doing something. As he states: 
the concept of the object of activity is a promising analytical tool providing the possibility of understanding not only what people are doing, but also why they are doing it. The object of activity can be considered the "ultimate reason" behind various behaviors of individuals, groups, or organizations. In other words, the object of activity can be defined as "the sense-maker," which gives meaning to and determines values of various entities and phenomena. Identifying the object of activity and its development over time can serve as a basis for reaching a deeper and more structured understanding of otherwise fragmented pieces of evidence (p.5).

Following this realisation, we used "argumentation", as the object of activity in our research study, as the main analytical tool for making sense of the various transformations that it went through during the two years the project was running; the specific processes through which this was materialised, are described in following sections of the paper.

\subsection{Research and Analytical Processes}

The research processes that were completed during the two years the project was running are concisely described in this section; a more detailed account of these processes along with the findings is given in subsequent sections of the paper, since a variety of research and analytical processes were followed in each phase of the project. Even though the main focus of this paper is to present the evolutionary course of the object of the activity of argumentation instruction, some details of the project, including some of its main findings, need to be reported here, so that the reader realises the broader context in which the various transformations of the object took place. For a more concise and detail account of the research project, see Author.

The study followed the learning actions of the expansive learning cycle methodology (see Figure 2). The expansive learning cycle is an expression of expansive learning theory, which is considered as a dialectical method of realising the essence of an object by trying to theoretically conceptualise the logic and the course of its origin, historical evolution and development, by looking into the emergence and resolution of its inner contradictions (Engeström, 1987, 1996); contradictions are said to be pervasive tensions that exist between the use and exchange value of any object (Engels, 1925; Marx \& Engels, 1968), often leading to change and development of both the object and the activity (Engeström, 1999). The expansive learning cycle may be realised through a sequence of epistemic or learning actions that also constitute the expansive learning cycle methodology (Engeström, 1987, 1996, 2001), which was the methodological framework that guided the whole research (see Author for more details). In this paper, we make use of the notion of the "springboard" (Engeström, 1987, Chapter 4) and the "microcosm" (Engeström, 1987, Chapter 5) from the expansive learning theory, as methodological and analytical tools for tracing and describing the reshaping of argumentation as the object of our activity

The expansive learning cycle begins when some of the participants in the activity begin to question the established practice, seeking for new possibilities. Through a historical analysis, the researcher tries to concretely describe the activity, its inner relations and inherent contradictions. Participants at the activity are encouraged to formulate qualitatively new models as a medium for resolving the contradictions, through the discovery of a springboard, the formulation of a general instrumental model and the construction of a microcosm. The springboard is defined by Engeström as:

a facilitative image, technique or socio-conversational constellation (or a combination of these) misplaced or transplanted from some previous context into a new, expansively transitional activity context during an acute conflict of a double 
bind character. The springboard has typically only a temporary or situational function in the solution of the double bind' (1987, Chapter 4).

Springboards are a medium and a pathway towards expansive solution and should not be considered as solutions in themselves. Concerning the finding of a springboard, Engeström (1987) argues that when participants are provided with a suitable language, they can envision the springboard by themselves based on their past experience. Through the formulation of the instrumental model, participants acquire a new general model based on their own historical insight, which can be either the object of the activity (e.g., the creation of a new model of the object in a work organisation) or the instrument of the activity (e.g., when participants collectively work out a systemic model for planning and controlling the implementation of a new instrument); this contributes significantly in a more productive application of the model and the formulating instruments, leading to a more efficient resolution of the presented contradictions. These processes can be facilitated through the construction of a microcosm through which the instrumental model is further examined, experienced and experimented through implementation in practice; a process that may lead to the transformation of the new model into the new form of practice. Microcosms are said to be "miniatures of the community upon which the new form of activity will be based. They are social test benches of the new activity, a temporary formation...a vehicle for transition from cooperation to reflective communication' (Engeström, 1987, Chapter $5)$.

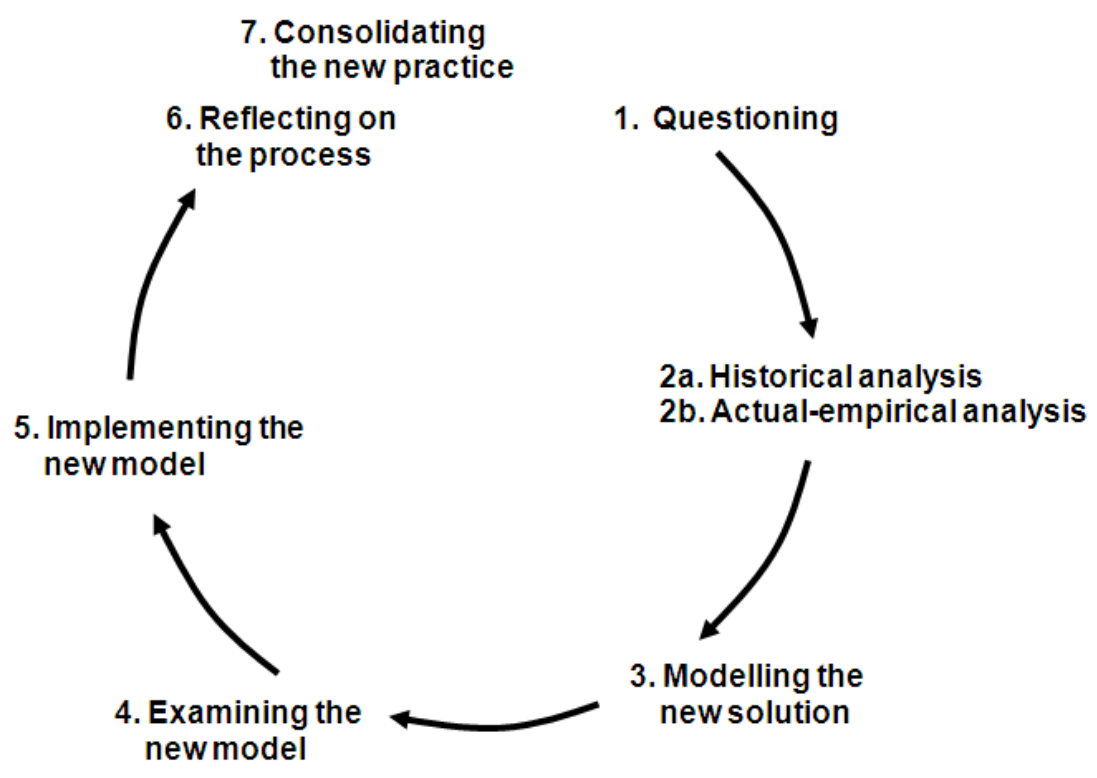

Figure 2. Sequence of learning actions in an expansive learning cycle (Engeström, 1999a, p.384).

The starting point of our research project was when the first author, as an in-service science education teacher in two primary schools in Cyprus, questioned the existing practice concerning argumentation in Year-6 science education and assumed, based on his personal teaching experience, that the unavailability of appropriate tools to support Year-6 students' effort to build sufficient and complete arguments was one of the reasons students face difficulties with argumentation. Nevertheless, this initial assumption had to be addressed by socially expanding the study to engage more stakeholders, such as other teachers, the science inspector and students, 
in a process of questioning and potential change. A detailed historical analysis of the existing practices concerning argumentation instruction was conducted during the first research year, so that the activity system of argumentation instruction in primary science education could be constructed and portrayed through the activity system model. Data collection included semistructured interviews with five teachers teaching primary Science Education for at least five years (Teachers 1, 2, 3, 4 and 5), a semi-structured interview with the science inspector, a yearly "Self-Reflective Teaching Diary" of the first author while being an in-service teacher in two primary schools through which argumentation episodes were recorded, and observation of four 80-minute Year-6 science education lessons in four other primary schools in Cyprus. Analytical methods included a qualitative discourse and content analysis of data collected, based on activity theory's guidelines (e.g., Engeström 1995, 2000, 2001). Following, various contradictions that existed within the activity systems recognised were identified and portrayed within the activity system model. As this process is described in detail elsewhere (Authors), further details of the preceding processes will not be mentioned here.

Following the historical analysis, the five teachers and the science inspector who were interviewed, expressed certain recommendations, so that the identified contradictions could be resolved and a new vision for promoting argumentation in primary science education could be realised. The notion of the "springboard" from expansive learning theory (Engeström, 1987, Chapter 4) was used as an analytical tool. Specifically, a qualitative content and discourse analysis of the interviewees' utterances was completed, through which an effort was made to recognise certain keywords and phrases in the utterances that could point to the identification of a springboard, in order to help participants envision a new way through which argumentation could be promoted in primary science education, emancipated from the previous tensions that seemed to be reported during the action of the historical analysis. This process led to the initial reshaping of the way the object of the activity of argumentation instruction was realised by the participants and is described in detail in section 4.2.

In order to facilitate the process of experimenting with this new way of promoting argumentation, a "microcosm" (Engeström, 1987, Chapter 5) was constructed, as a social test bench through which the new model could be further examined, experienced, experimented in practice and reflected upon. The microcosm that was constructed, which run throughout the second year the research was running, comprised of four meetings, lasting two hours each on average, in which a community of four science education teachers took part to discuss and share practices they were experimenting with regarding argumentation in their science lessons at primary school. Teachers 1 and 2 took part in the meetings along with two other teachers, Teachers 6 and 7, who both had an over ten-year experience in teaching primary science education. All teachers taught in different schools at the time. The meetings were coordinated by the first author and were audio-recorded.

At the beginning of Meeting 1, the coordinator of the meetings introduced the new model of promoting argumentation in science education to the participating teachers, envisioned through the previous phase of the research. The object of this activity was more or less given to them by the coordinator, as ready-made, raw material to work with. Teachers initially engaged in a discussion through which they tried to grasp an understanding of the motive of the activity of argumentation instruction and propose initial practices through which they could try to promote argumentation in their lessons. Their following task was to test these practices in their lessons and meet in the subsequent three meetings that were organised, to examine, reflect upon and share these experiences in order to work out ways of moving forward. 
The data relevant to the scope of this paper that were used, collected during the second year the research was running, were the audio-recordings of the discussions that took place during the four meetings (nine hours of recordings), audio-recordings of the participating teachers' Year-6 science lessons in their schools (24 argumentation implementations, seven hours of recordings), and examples of students' written work with argumentation that teachers shared between them during the meetings. The overall effort was to trace through qualitative content and discourse analysis of the data collected, based on activity theory's analytical guidelines (e.g., Engeström 1995, 2000, 2001), on inductive analysis (Thomas, 2006) and on various theoretical notions deriving from Marx's (1973), Leont'ev's (1978, 1981) and Engeström's (1987) work on the object of activity used as analytical tools (e.g., objectification of the need, use and exchange value, structure of the activity), evidence that could help us realise any possible reformulation of the object of the activity of argumentation instruction during the second research year. The process is described in detail in section 4.3.

\section{Findings}

\subsection{Introduction}

We begin by reporting on how recommendations made by stakeholders, on resolving identified tensions related to the implementation of argumentation in primary science education, led to an initial transformation of "argumentation", as the object of the activity, during the first year the research was running. Following, we will report on the various re-interpretations or transformations that the object went through during the second research year.

\subsection{Initial Transformation of the Object of the Activity of Argumentation Instruction (Research-Year 1)}

"Argumentation" describing the object of the activity of argumentation instruction in primary science education in Cyprus, was initially defined as the skill that students should have or attain in order to express the knowledge they obtain to support a claim or for making links between facts they learn or for transferring the attained knowledge into instances of their everyday life. This was not arbitrarily decided but was based on the initial analysis of the interviews of the teachers (Teachers 1 to 5) and the science inspector during the phase of questioning and historical analysis of the expansive learning cycle, in which they all defined similarly the object of the activity of argumentation instruction (see Authors for more details).

Furthermore, the analysis of the data collected during the same phase, also reported in Authors, helped us identify various contradictions which referred to the pervasive, accumulating tensions that teachers were facing in their effort to implement argumentation in primary science education. In an effort to resolve the identified contradictions and envision a new way of promoting argumentation in their science education lessons, certain recommendations were made by the participating teachers and the science inspector, in a way of also addressing their own needs and motives. The reporting of the findings that refer to this paper begins at this point.

Participants' recommendations, based on a qualitative content analysis of the data, were clustered into two groups, which were generated from the data by using inductive analysis (Thomas, 2006). The ones referred to more general guidelines and pointed out teaching practices and teaching tools which, as stakeholders reported, may have already been used in science lessons. The others noted specific guidelines which someone might argue that they referred to 
ways not yet conceptualised, but envisioned by stakeholders as appropriate ways of promoting argumentation in science education.

Briefly reporting on the first cluster of practices and tools, as recommended by the teachers and the science inspector, argumentation should be practiced regularly in science education. Also, acquired content knowledge was reported as an important element while the engagement in experimental work seems supportive of students' argumentation efforts. As for the teachers' role, it was suggested that teachers should prepare and organise their lessons in a way that argumentation can be promoted by engaging students in dialogic discussions and by using appropriate prompts and question prompts.

As for the second cluster of recommendations, these were put forward by Teachers 1 and 3 and the science inspector. The science inspector suggested that argumentation should be practiced in a structured and guided way through dialogic discussions organised by the teacher. Teacher 3 proposed that students should be assisted to:

realise more clearly the picture, the bigger picture...understand how each event is connected to the other and to something bigger maybe; to be able to build a mental construction inside their minds; to see how the different pieces of the puzzle link together, to put them together and then to say, to reach a conclusion and reason about this conclusion and do this thing.

From his viewpoint, Teacher 1 suggested that there is a need that students' argumentation efforts are practically scaffolded by providing students with a specific, structured course that could help them realise the essence of what an argument is and to able to establish connections between the various elements of the argument:

initially, their arguments should be guided in some way...In order to reason, they have to know a way through which they could reason about this, they have to connect all the things that they know and also support them, give an example...If we give them this structure at the beginning, I believe that we can help them give arguments on their own.

Teacher 1 seemed to substantiate his recommendation on previous teaching experience when he implemented argumentation in a Modern Greek lesson in a structured and guided way by providing students with a course of steps to follow in order to build their argument.

Certain keywords could be identified in the above statements that helped us take the next steps forward in the research effort. Keywords such as "structured and guided argumentation", "structure", "the bigger picture", "mental construction", "different pieces of the puzzle" and verbs such as "link" and "connect" seem to point to a specific approach envisioned by stakeholders in order to support students' argumentation efforts and help them overcome the difficulties they face with argumentation; an approach that suggested that structured argumentation should be fostered based on a mental schema which could scaffold students' efforts to build arguments via linking together subsidiary pieces of knowledge, leading thus to the reformulation of the object of the activity of argumentation instruction (Figure 3). 


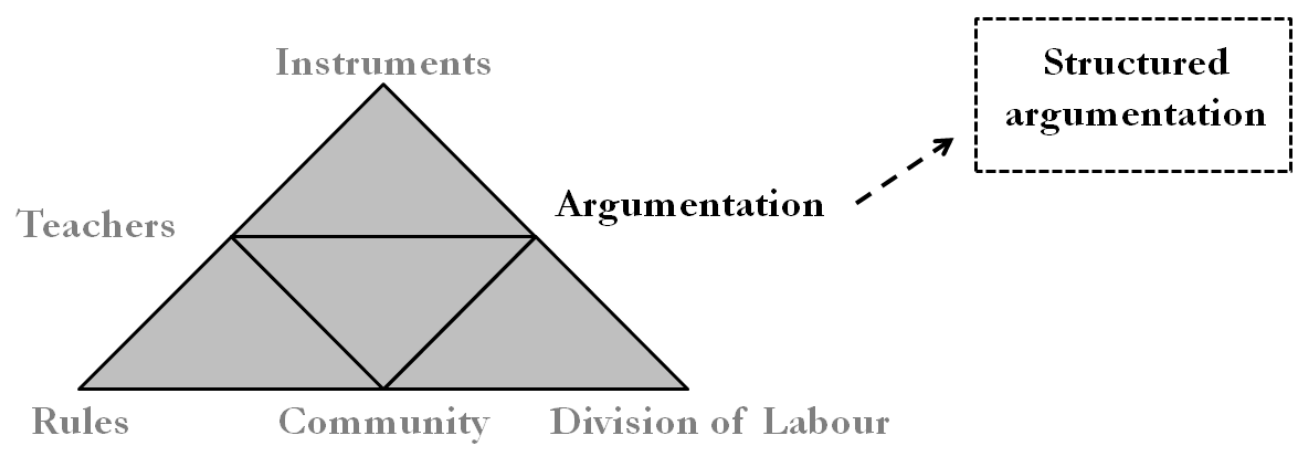

Figure 3. The initial reformulation of the object of the activity of argumentation instruction.

At this point, since the teachers and the science inspector referred to a more structural approach to argumentation by proposing the use of a specific structure that could be used for helping students link together different pieces of knowledge to build an argument, we questioned whether Toulmin's Argumentation Pattern (Toulmin, 2003) (TAP), whose form fits this definition, could play the role of such an instrument; as a reminder, TAP is an argumentation framework that focuses on a more structural form of argumentation, regarding an argument as consisting of five components: the claim, the data, the warrant, the rebuttal and the backing (Figure 4). Additionally, it was also questioned by the researchers whether TAP could acquire, in Engeström's (1987) words, the role of a springboard, and function as a temporary, initial solution to the identified contradictions.

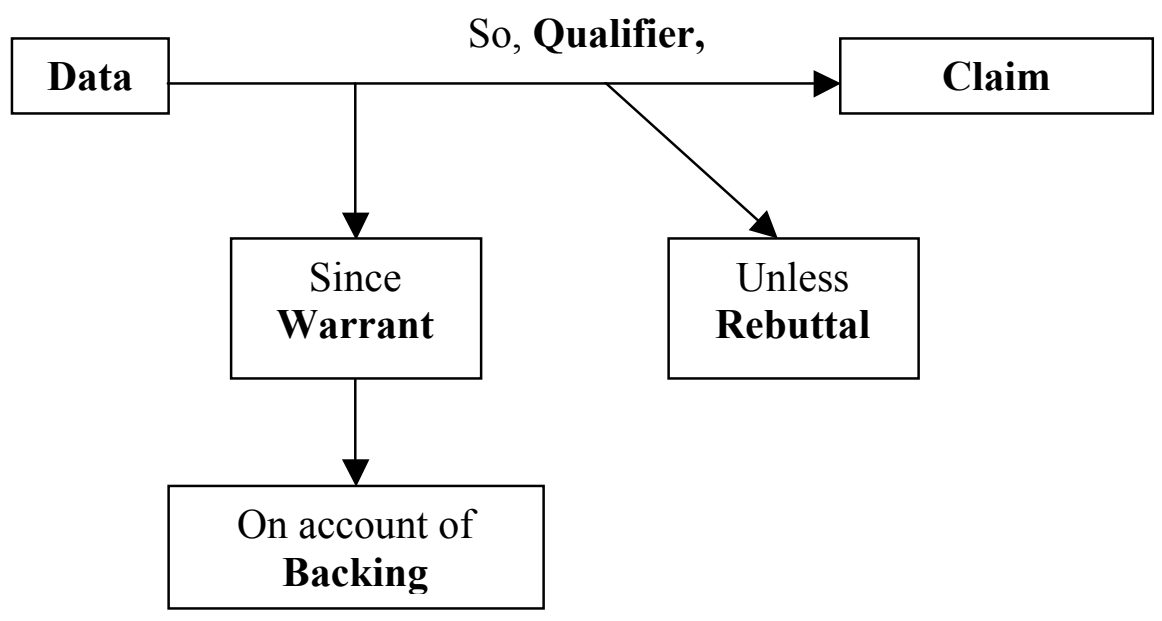

Figure 4. Toulmin's argumentation pattern (Toulmin, 2003, p.97).

Initially, we examined whether TAP could be seen as a springboard. As defined, a springboard is "a facilitative image, technique or socio-conversational constellation (or a combination of these) misplaced or transplanted from some previous context into a new, expansively transitional activity context during an acute conflict of a double bind character" (Engeström, 1987, Chapter 4). As mentioned, Teacher 1 substantiated his recommendation for using a structured course of work as a scaffold for argumentation, based on a past experience that he had with such a structured way of dealing with argumentation, in a lesson he did in Modern Greek. It could be argued thus that Teacher 1 suggested a "technique", to use phrases from the 
proposed definition of the springboard, "transplanted from some previous context into a new...activity context” (Engeström, 1987, Chapter 4) in order to realise a new way of helping students overcome the difficulties they have with argumentation in science. Based on this line of logic, TAP could be seen as the springboard. But in order to address the first question posed in the previous paragraph, it might be argued that it needed to be further examined through supplementary research whether TAP, seen as a springboard, could play the role of the mental schema that could scaffold students' effort to build complete arguments by drawing links between subsidiary pieces of knowledge and whether this may help them overcome current difficulties they face with argumentation. In order to achieve this, the research needed to progress to the next phase which aimed in realising a new teaching and learning practice for promoting argumentation in primary science education through the implementation of TAP.

By the completion of this phase of the research, two reformulations of the initial object of the activity system of argumentation instruction could be noticed, based on a process of an objectification of stakeholders' needs (Leont'ev, 1978), expressed through their own recommendations. The initial object, defined as "argumentation" was reformulated to being "structured argumentation" based on stakeholders' recommendations and it was then reconceptualised again to be defined as "structured argumentation based on TAP", by recognising TAP as having the role of the springboard and potentially, functioning as a temporary, initial solution of the tensions that were identified.
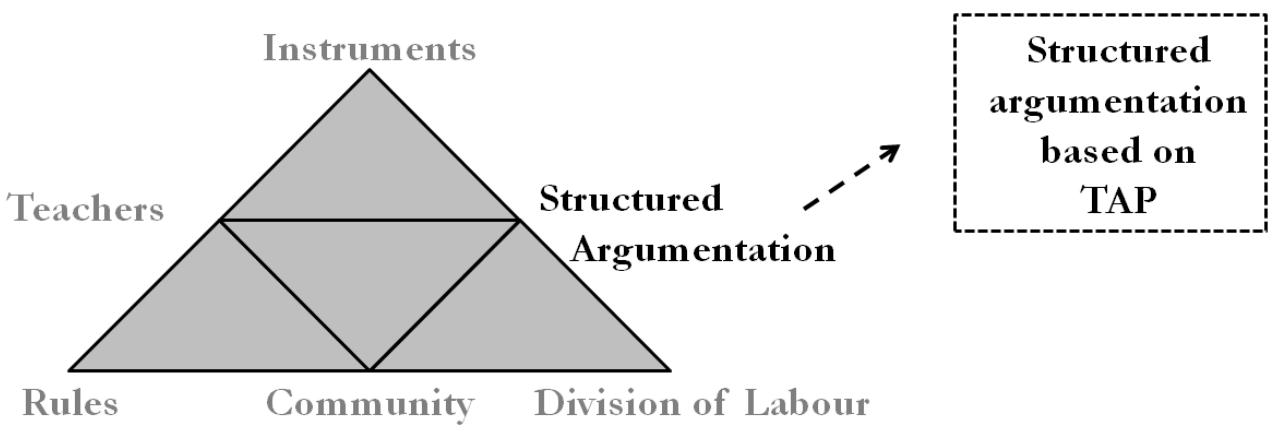

Figure 5. "Structured argumentation based on TAP" as the new object of the activity of argumentation instruction.

\subsection{Transformations of the given-new Object (Research-Year 2)}

"Structured argumentation based on TAP", which was realised as the object of the activity of argumentation instruction during the first research year (see Figure 5), was introduced to the four participating teachers (Teachers 1, 2,6 and 7) at the initial meeting of the second research year, as the given-new object of the activity of argumentation instruction, for which they were asked to work out specific social practices in order to materialise it, in an effort to potentially help them overcome the limitations of the established activity, recognised through the historical analysis. Nevertheless, throughout the second research year, each teacher seemed to realise and personify this object in his/her own personal, unique and meaningful way based on his/her teaching needs, the needs and the understanding of his/her students and by being influenced by the ongoing processes within the activity system of argumentation instruction, all being discussed during the arranged meetings. Through this process, the given-new object seemed to be re-interpreted, reconstructed and reshaped into a meaningful entity for each teacher. 


\subsubsection{Reshaping the Object of the Activity during Meeting 1}

As mentioned, "structured argumentation based on TAP" was introduced to the teachers at the initial meeting of Research Year 2, as the given-new object of the activity of argumentation instruction. During Meeting 1, the four teachers discussed at length issues concerning the "essence of argumentation" and the "essence of TAP", as the two subcomponents of this given-new object. Evidence from the analysis of the data indicated that, as the discussion evolved during the meeting, teachers gradually began to reconstruct the way they realised argumentation, especially when TAP was introduced in the discussion. Figure 6 is illustrative of this claim, presenting a chronological or historical evolution of teachers' views during Meeting 1. The discussion on the essence of the TAP, when the pattern was introduced into the discussion by the coordinator, revealed that teachers were already beginning to engage in an ongoing process of reformulating TAP as well. This specific discussion evolved around the essence of the constituent components of the model, the sequence in which these components should be expressed, the multifaceted form of the model and the difficulties teachers expected that students would face when using the model.

Concerning the sequence someone should follow to build a TAP argument, teachers did not seem to reach a common decision whether the process should follow a top-down or a bottomup process or whether the claim or the data should be the starting point of the argument. Regarding the components of TAP, teachers discussed specifically about the data and whether the data should be regarded as a given statement to be further elaborated, an observation that students might make through experimentation, a given fact or an interpretation. Concerning the meaning of the warrant, the teachers reached a common understanding, expressed by Teacher 6 , which seemed to resemble the definition of the warrant as given by Toulmin (2003). As suggested, the warrant was regarded as a supplementary and explanatory statement that could be implicitly inferred, which also indicated one of the main differences between the warrant and the data; that the data can be explicitly expressed whereas the warrant might be inferred. Concerning the nature of an argumentation question, it was specifically discussed whether a "which" or a "why" question would be more appropriate to promote argumentation. Teachers also referred to the possible difficulties that students might face when dealing with TAP, related to the multifaceted form of the model, the difficulty to draw links between the claim and the data and the possible difficulties they would face with grasping the true meaning of the warrant, the backing and the rebuttal.

Conclusively, it may be argued that teachers began to reformulate what argumentation meant to them and personify the essence and features of TAP right from the initial meeting, based on their own needs, motives and expectations. 


\section{Argumonemitation}

Teachers 2, 6 and 7

- Argumentation as an integral part of Science Education

$2 \quad \begin{aligned} & \text { Teacher } \mathbf{1} \\ & \text { Teacher } 6\end{aligned} \quad \begin{aligned} & \text { A process already being practiced } \\ & \text { by teachers but teachers are not } \\ & \text { aware they are practicing it }\end{aligned}$

- A discussion around their own misconceptions

- An effort to backup a claim put forward - descriptive sentences or observations cannot be considered as arguments

aware they are practicing it

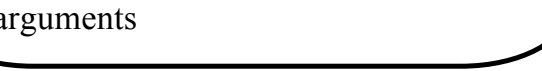

\section{Avgrumeint}

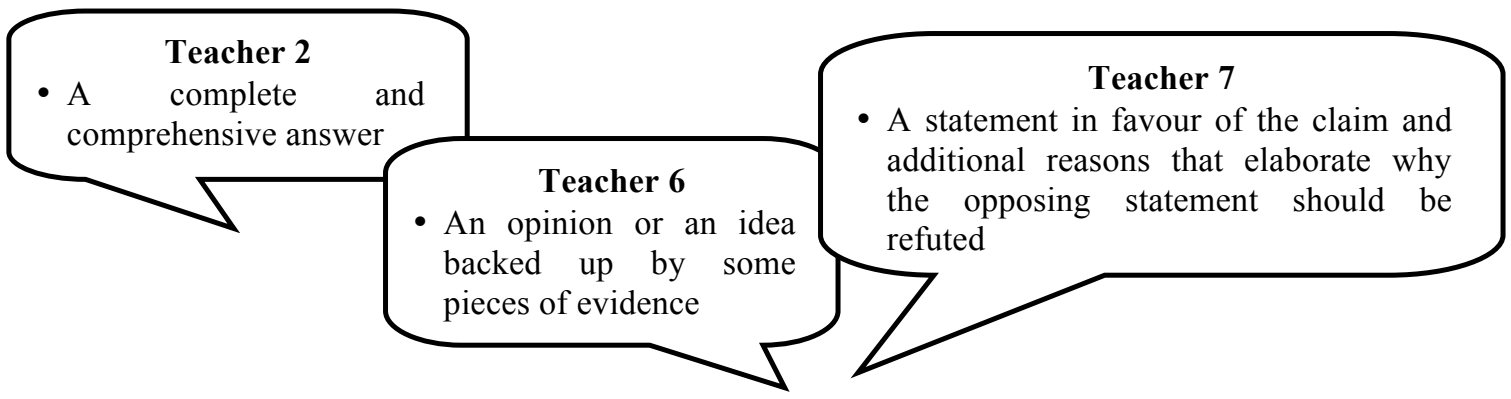

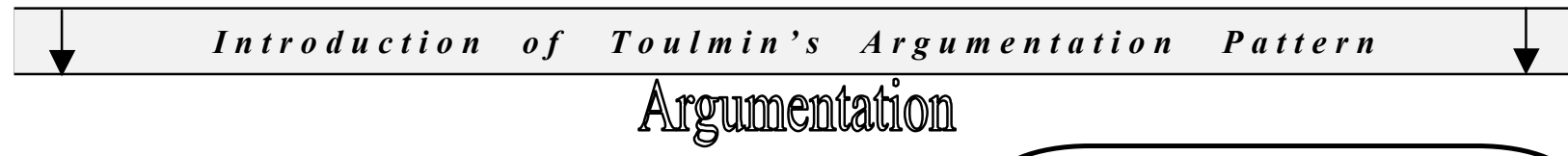

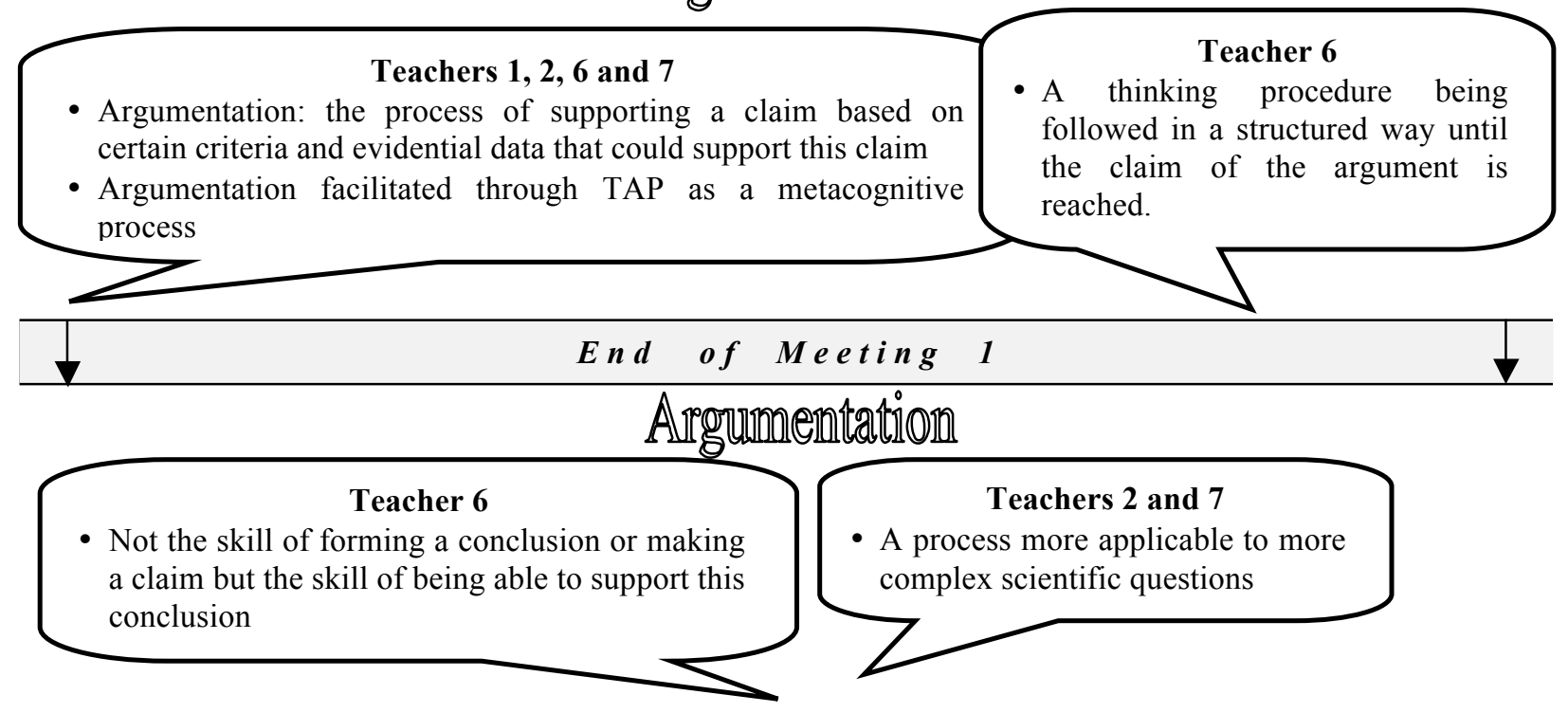

Figure 6. A chronological evolution of teachers' views during Meeting 1. 


\subsubsection{Transformations of the given-new Object during Research-Year 2}

This section continues the discussion that concerns the transformations of the given-new object of the activity of argumentation instruction, defined as "structured argumentation based on TAP", but focuses specifically around the contradictions that arose during the second research year. The recognition of these contradictions proved to be a fruitful way of gaining access in how teachers realised the object of the activity and how this understanding evolved throughout the year. These contradictions derived from the pervasive tensions that emerged throughout the teachers' yearly effort to implement "structured argumentation based on TAP" in their science lessons, expressed during the discussions that took place at the additional three meetings that were arranged during the year. Here, the discussion around these contradictions focuses on the themes of the "essence of argumentation" and the "essence of TAP", in accordance to the paper's devotion on reporting the findings by following the object of the activity. Additionally, this section also presents the way these tensions seemed to be resolved based on recommendations expressed by teachers during the meetings, making in this way a twofold effort: not only to illustrate the object's contradictory nature but also the object's ongoing reconstruction, realised through the teachers' recommendations.

The main contradiction that was identified regarding the essence of argumentation, pervasive in all four meetings that were arranged, referred to a contradiction within the object of the activity system of argumentation instruction; that between the realisation of argumentation as a discrete skill and the realisation of argumentation as a skill of using or reporting on scientific knowledge (Figure 7). Teachers often expressed the concern during the meetings whether argumentation is indeed a discrete practice or skill that students may have or whether it is a skill of being able to evoke scientific content knowledge that they were taught during past lessons. To support this claim, they also drew examples from their lessons. Teacher 7 for example, expressed concerns during Meeting 3, about the factor that seemed to be contributing to his students giving adequate arguments in a set of questions on electricity; he wondered whether this occurred due to their gained ability to use appropriate argumentation strategies based on TAP or if it was merely due to their understanding of scientific content knowledge. He concluded that: "I tend to believe that those who answered the question correctly had done so because they had understood correctly the concept of the circuit connected in series or in parallel. The emphasis was not on argumentation, it was more on providing scientific knowledge" (Meeting 3).
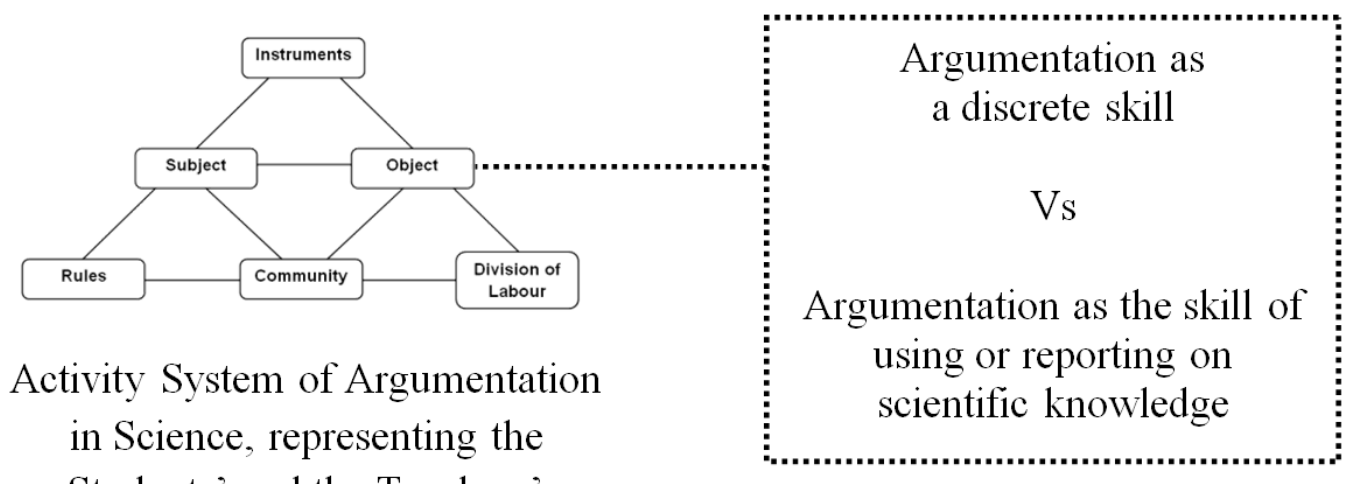

Activity System of Argumentation

in Science, representing the

Students' and the Teachers'

Perspective

Figure 7. Contradiction identified within the object of the activity. 
Teachers made several theoretical and practical recommendations for overcoming this contradiction. Specifically, they emphasised that the importance of pre-existing knowledge for engaging in argumentation should not be dismissed by teachers. Pre-existing knowledge ought to be realised as a useful tool, a pre-condition and an inherent process of argumentation:

Teacher 2: Ok, but in order to be able to backup their argument they have to get information from somewhere; in this case, they will get this from an informational source, will they not?

Teacher 1: There has to be some teaching in order to have better understanding to be able to build an argument (Meeting 1).

Additionally, they suggested that argumentation should be recognised as a useful tool for helping students make the knowledge they possess more specific and overt. Through the many discussions that took place during the meetings concerning the role of pre-existing knowledge, teachers managed to reconceptualise their own understanding about argumentation, suggesting that argumentation should be realised as a synergy between the awareness about the argument's structural components and knowledge about the specific scientific content: "In order to engage productively with argumentation, it means that they already know the structural components needed for the argument and they also have certain pieces of knowledge that they will try to fit in these components" (Teacher 6, Meeting 3). A useful practice suggested for overcoming the contradiction identified concerned the facilitation of argumentation through appropriate, complex and challenging questions.

Two additional contradictions that were identified referred to the way teachers realised the essence of TAP and the way it should be implemented in practice. In order to conceptualise these contradictions, we realised TAP as a commodified object, having both a use value and an exchange value; based on the theoretical definitions of these two values (Marx, 1973) (see section 2.1.1), the use value of TAP refers to the value that it initially has as a useful product coined by Toulmin (2003) with the intention of satisfying the need of building solid and complete arguments while its exchange value refers to the value that the model acquires due to its exchangeability between individuals, in our case between the teachers and the students, and the way it can be influenced by explicit or implicit social conditions. The reason for using these theoretical notions lies on the fact that we want to exemplify the tensions that arose between TAP's initial value as a theoretical model and its acquired value when this model was exchanged in practice and was implemented in real teaching and learning conditions.

The first tension that was recognised, refers to the contradiction that seemed to exist between the use value and the exchange value of TAP (Figure 8) and more specifically, to the double bind that Teachers 1 and 7 seemed to be facing, noticed between the motive to implement argumentation based on TAP, as originally suggested by Toulmin (2003), and the practical difficulties this seemed to be inducing for the students. This tension, as teachers reported, derived from the argument's multifaceted schematical form, the confusion that the warrant seemed to be inducing to students and a confusion about what the starting point of the argument should be. For example, Teacher 7 reported that by trying to follow the argument's multifaceted form, he felt that the argument "kind of lost its naturalness and its coherence and its flow, but [I] thought that it had to be followed in this way as a first contact with the subject" (Meeting 3). The second tension that was recognised, refers to the contradiction that seemed to exist between the use value and the exchange value of the rebuttal (Figure 9) and specifically, to the double bind that seemed to exist between the importance of the rebuttal as an integral part of a TAP argument, noted mainly by Teachers 2 and 7, and the difficulties and the confusion it created for 
students, noted mainly by Teachers 1 and 6. As Teacher 6 noted during Meeting 3: “...based on the abilities of my students and on what we discussed about what the rebuttal is, I decided that I would not teach anything about the rebuttal because I realised that they would find it difficult". Other supplementary difficulties that students faced with TAP was the difficulty in discriminating between the warrant and the data and in identifying and expressing a warrant.

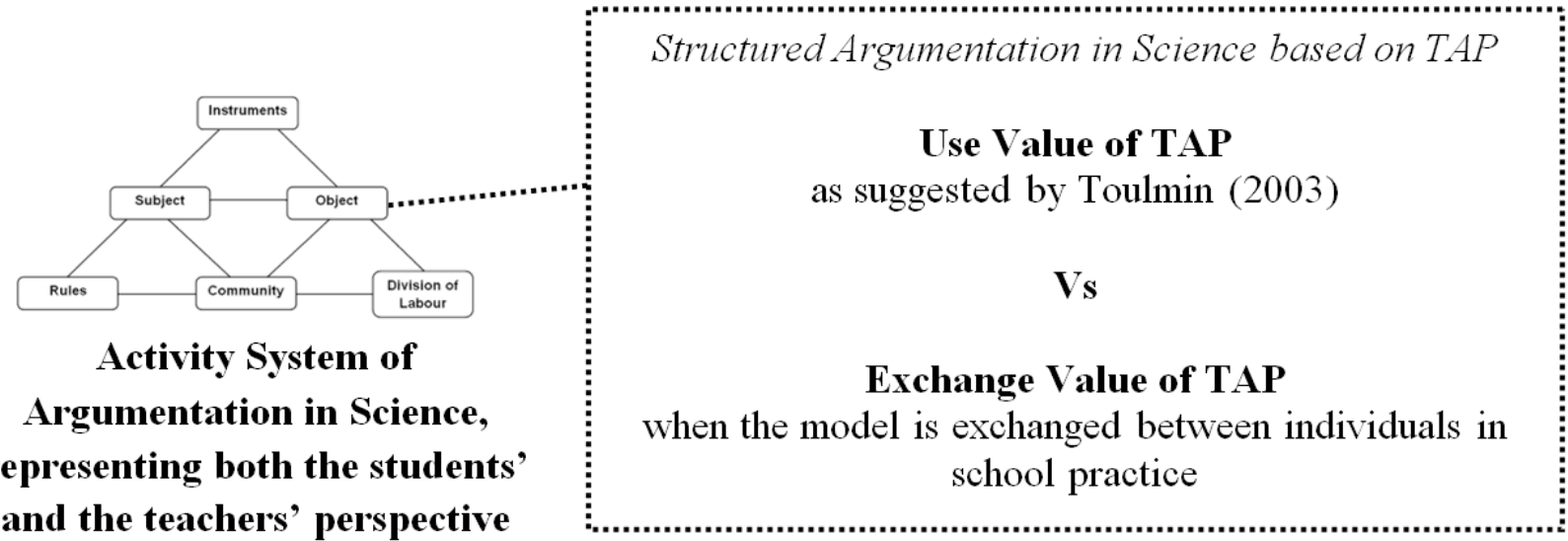

Figure 8. Contradiction identified between the use value and the exchange value of TAP.

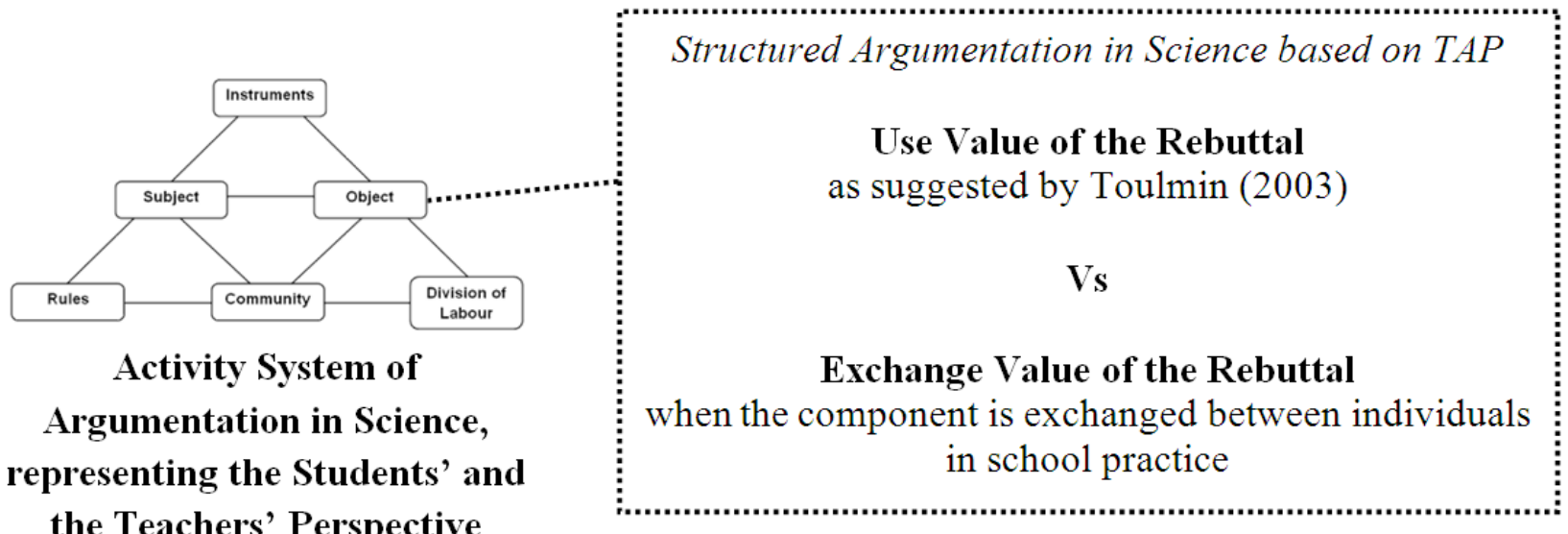

Figure 9. Contradiction identified between the use value and exchange value of the rebuttal.

Through the pervasive tensions that teachers came across with while engaging with TAP, read as contradictions, and the recommendations made in order to overcome these, we could argue that teachers engaged in a process of reformulating TAP, and consequently the object of their activity, based on their personal needs and motives; a process named by Leont'ev (1978, section 3.2) as the objectification of the need or, in Marx's (1973) words, a process through which TAP as the product, stepped outside the societal boundary, was objectified, and was exchanged and consumed in practice in order to serve the pending individual needs that existed. An interesting observation related to this claim is that teachers did not seem to reach a consensus concerning the various issues discussed at the meetings, but chose to make their own decisions 
concerning the course of work that they would follow in order to implement argumentation in their own lessons. For example, Teachers 1 and 6 chose not to use the rebuttal in their lessons because they thought that this component created much confusion to their students, whereas Teacher 2 not only did he incorporate the rebuttal in students' argumentation efforts but he also realised it as a really significant component for provoking interesting discussions amongst his students. Also, Teacher 7 decided to make use of the term "so" in the warrant box as a reminder to students to express a warrant, in order to help them not only to be reminded to identify and express a warrant but also to engage in a mental process of making the discrimination between the warrant and the data, overcoming in this way the difficulty that existed. He also used a nondiagrammatical form of the pattern and a form that helped his students express the pattern's components in a serial way in order to help them overcome the difficulty they were facing with the pattern's multifaceted form. Other alterations of TAP made by teachers throughout Research Year 2 related to the components' sequence, the order of claim and data and the name and the essence of the components as taught by each teacher. Table 1 presents an example of how Teacher 2 in specific defined the essence of each component of TAP.

\subsubsection{A possible Interchangeability between the Components of the Object and the Tool of the Activity}

We begin this section with a reminder to the reader that "structured argumentation based on TAP" was introduced to the teachers as the object of the activity during Meeting 1 (see Figure 5). Teachers were expected to implement TAP in science education and through a cyclic process of experimentation, reflection and evaluation, realise appropriate ways of engaging students with the TAP model in order to enhance their argumentation skills; something that may be seen as the activity's anticipated outcome. As time progressed and as teachers and students seemed to become more accustomed and more confident in using the model, a shift in the way teachers realised the object of their activity began to be evidenced; to support this claim, we will refer to certain episodes during the discussions that took place at the meetings.

Noting the significance of TAP as a thinking tool for his students during Meeting 3, Teacher 2 noted that:

I believe that it will help some students in the long run, not all of them, for sure. Many things that we do cannot be measured, are not measureable, not now, not even later, but they get engraved in your mind. They are recorded in your mind and they stay there. And especially this here because it is a process, it will remain in their mind. In some students it will remain in their mind and they will use it in the future without even knowing they are using it.

Further, during Meeting 4, Teachers 1,2 and 7 expressed the belief that, through practice, students could ultimately internalise and automate the TAP process in their minds and be able to engage in argumentation without external tools to mediate their effort. Two episodes from this meeting are presented here as examples to support this claim:

Episode 1:

I have given them a diagram structured in a way that it helps them organise their thinking and I am hoping and expecting that, if I apply this once or twice more, at the end they will not be in need of the diagram. I feel that at the end they will be freed from it (Teacher 1).

Episode 2:

Teacher 7: The important thing for the students is to be able to begin their answer and 
complete this answer without you intervening all the time with supplementary questions to help them externalise what they are thinking.

Teacher 2: And basically, these questions are the diagram [TAP]. They are the keys. Teacher 7: Yes. Exactly. Because that is what we do. A student says something, then he stops, then we pose another question to elicit the next thing. The point is to eventually be able to say what he wants in a complete way. 